\title{
HIGHER SCORES ON THE MINI-K LIFE HISTORY BATTERY ARE ASSOCIATED WITH GREATER DISGUST SENSITIVITY ON THE THREE DOMAINS OF DISGUST SCALE
}

\author{
MICHAEL J. FREDERICK, HILARY R. KEIL, RAMY BASSIONI, AND \\ HUMAMA KHAN* \\ University of Baltimore
}

\begin{abstract}
Disgust is a universal emotion that promotes protective behaviors in three distinct domains: sexual, moral, and pathogenic. There is considerable individual variation in sensitivity to disgust, and past research suggests individuals with slower life history strategies are more sensitive to stimuli that provoke pathogen and moral disgust. We hypothesized that such individuals would also be more sensitive to disgust in a sexual context. Two hundred seventyseven participants completed the Mini-K Life History Battery and the Three Domains of Disgust Scale. A slower life history strategy (as reflected by a higher Mini-K score) was associated with increased sensitivity to sexual, pathogen, and moral disgust. Removal of items with potential overlap did not affect the significance of the results. These findings suggest that the K-factor of life history is associated with increased disgust sensitivity across all three domains.
\end{abstract}

Keywords: life history, disgust sensitivity, pathogen disgust, sexual disgust, K-factor

\section{INTRODUCTION}

\section{Life history theory}

Life history theory is an evolutionary framework that focuses on the ways organisms allocate limited environmental resources (MacArthur \& Wilson, 1967; Stearns, 1976, 1989; Rushton, 1985). The theory suggests individuals will seek to optimize the investment of resources, engaging in a series of trade-offs in order to allocate resources for maintenance, growth, and reproduction (Chisholm, 1993). The environment that an individual is exposed to early on, and the availability of resources while growing up, can shape an individual's

* Corresponding author: Michael J. Frederick, Division of Applied Behavioral Sciences, University of Baltimore, Baltimore, MD 21201. E-mail: mfrederick@ubalt.edu

This is an open-access article distributed under the terms of the Creative Commons AttributionNonCommercial 4.0 International License (https://creativecommons.org/licenses/by-nc/4.0/), which permits unrestricted use, distribution, and reproduction in any medium for non-commercial purposes, provided the original author and source are credited, a link to the CC License is provided, and changes - if any - are indicated. 
behaviors throughout the lifespan (see Ellis, Figueredo, Brumbach, \& Schlomer, 2009).

Life history theory provides a framework for studies into how organisms allocate time and resources to fundamental goals, such as mating and parenting (Hackman \& Hruschka, 2013). Certain behaviors are thought to cluster together to form predictable life history strategies, and these strategies are set in response to levels of environmental harshness and uncertainty during development (Copping, Campbell, \& Muncer, 2013). Other things being equal, an individual from a harsh environment will tend to display a 'fast', rather than a 'slow', life history strategy (Figueredo, Vásquez, Brumbach, \& Schneider, 2004; van Leeuwen, Koenig, Graham, \& Park, 2014). Such a strategy would involve investing in early and frequent reproduction, rather than delaying reproduction until substantial resources are acquired and an ideal partner is secured. The advantage of this strategy in a harsh environment is clear: when mortality risk is high, any delay in reproduction will increase the risk of dying before one's genes are passed on.

Fast life history strategies are defined as faster maturation, shortened lifespan, early and unrestricted reproductive behavior, and less parental investment in offspring (Ellis et al., 2009). Generally speaking, fast life history individuals devote more time and energy to obtaining mates and having children, while investing relatively less in each child (Cabeza de Baca \& Figueredo, 2014). This leads individuals to become pregnant at younger ages, have higher risks of contracting sexually transmitted diseases, have lower rates of attachment to romantic partners, and be more prone to sexual promiscuity and sexual variety (Chisholm, 1993; Chisholm, Quinlivan, Petersen, \& Coall, 2005; Figueredo et al., 2006; Koehler \& Chisholm, 2007; Wilson \& Daly, 1997).

Slow life history strategies are associated with greater somatic investment and the pursuit of long-term goals (Dillon, Adair, Wang, \& Johnson, 2013). Individuals who have slow life history strategies delay mating, display increased sensitivity to social norms, and have higher levels of cooperative behavior (Figueredo \& Rushton, 2009). Slow life history also implies more stable relationships between parents in order to invest in parental care until offspring reach reproductive age (van der Linden, Klaveren, \& Dunkel, 2015), which falls in line with individuals producing fewer offspring in order to invest more in those offspring (Dillon, Adair, \& Brase, 2015). These individuals are focused on long-term planning and exhibit higher levels of executive functioning (see Cabeza de Baca \& Figueredo, 2014). Due to investment in long-term planning and overall health, individuals with slow life history strategies display an aversion towards sexual risk much more so than individuals who display fast life history strategies (Dillon et al., 2015). 
In terms of the specific factors that may predispose one towards a faster strategy, stressful environments high in extrinsic mortality, morbidity, and family instability have been shown to be associated with earlier sexual maturity (Ellis, 2004) and a younger age of first reproduction (Störmer \& Lummaa, 2014). Lower self-reported socioeconomic status during childhood has also been reported to be a predictor of a faster strategy (Griskevicius, Delton, Robertson, \& Tybur, 2011a; Griskevicius, Tybur, Delton, \& Robertson, 2011b). Other research has found lower birth weights to be associated with faster life history strategies (Nettle, Coall, \& Dickins, 2010; Frederick, 2012).

\section{Disgust}

Recognizable across cultures, disgust is one of humanity's most basic emotions (Ekman, 1992). Early research on disgust was primarily concerned with humanistic attitudes towards food (see Olatunji, Adams, Ciesielski, David, Sarawgi, \& Broman-Fulks, 2012). This led to the view that disgust is merely a protective function related to ingestion that can now be observed across multiple domains (Rozin, Haidt, \& McCauley, 1993). Indeed, feelings of disgust protect us from toxins in food, bacteria in feces, and pregnant mothers from ingesting something potentially harmful to a developing fetus (see Buss, 1999). However, subsequent observations have led researchers to broaden this initial conception, as many disgust-provoking stimuli are not related directly to food (see Rozin, Haidt, \& McCauley, 2008). Feelings associated with disgust include not only distaste, but also anger, revulsion, and disapproval. These feelings, combined with physiological reactions, prepare the individual to avoid and reject the source of the disgust emotion and to treat it as a potential threat (Rozin et al., 2008). Thus, the disgust reaction may act as a generalized psychological and physiological defense mechanism (Druschel \& Sherman, 1999).

The moral attitudes surrounding the word disgust occur cross-culturally (Haidt, Rozin, McCauley, \& Imada, 1997). Although the disgust emotion is believed to have evolved initially as a defense against toxins and disease, it is now triggered by perceived ethical violations as well (Rozin et al., 2008). This likely represents a case of exaptation, in which a preexisting adaptive response has assumed a new functional role. Rights violations also trigger the emotion of anger, but physiological and verbal disgust responses occur independent from these anger responses (Cannon, Schnall, \& White, 2011; Nussbaum, 2006). When focusing on the consequences of an immoral act, individuals tend to exhibit anger, and those who have such anger directed at them tend to feel guilt (Giner-Sorolla \& Espinosa, 2011). Conversely, disgust seems to result when the 
person responsible for an immoral act is viewed as having a fundamentally bad character (Haidt, 2003; Rozin et al., 2008), and being the object of disgust seems to elicit shame more so than guilt (Giner-Sorolla \& Espinosa, 2011). It has been suggested that the functional reason for this anger/disgust distinction is that anger is more useful for correcting the mistaken behavior of someone who is basically good, whereas disgust will prompt one to avoid all interactions with someone deemed to have bad moral character (Fischer \& Roseman, 2007). In support of this, Giner-Sorolla and Chapman (2016) reported that although participants felt greater anger in response to a scenario in which a man beats his girlfriend when he catches her cheating, they felt greater disgust when the scenario involved beating the girlfriend's cat instead. Thus, violence against a human was seen as more wrong, but violence against an innocent animal indicated a more severe character flaw and was more likely to elicit feelings of moral disgust.

Disgust is clearly a valuable emotion to possess from a survival standpoint and one that may serve a specialized function with regards to sexual reproduction. Incest is considered a disgusting act cross culturally (Haidt, McCauley, \& Rozin, 1994). Females report higher levels of sexual disgust sensitivity than males (Tybur, Lieberman, \& Griskevicius, 2009a). Rempel and Baumgartner (2003) found that desire to participate in a range of varying sexual behaviors was negatively correlated with disgust sensitivity. Fessler and Navarrete (2003) found that disgust sensitivity decreases with age, and that presumed conception risk was positively correlated with sexual disgust sensitivity. These findings support that notion that the emotion of disgust serves to enhance survival and reproduction by promoting avoidant behaviors that help protect one from being exposed to potentially harmful things in the environment, including high-risk sexual encounters.

If sexual disgust is a distinct type of disgust that is experienced crossculturally, this suggests that it serves some fitness-enhancing function. Some theorists have suggested that the function is to prevent us from recognizing our own animal nature (Haidt et al., 1994; Rozin et al., 2008). This is known as the animal reminder perspective. However, more recently others have suggested that the true function of sexual disgust is to protect us from incurring the risks associated with having 'costly mates' (Fessler \& Navarrete, 2003; Tybur, Lieberman, \& Griskevicius, 2009a). These risks may include exposure to sexually transmitted diseases, conception with a low-quality mate, or reputational costs associated with being viewed as promiscuous or high in disease risk (see Tybur et al., 2009a).

When pursuing a slow life history strategy, one goal is to delay reproduction until resources are acquired and a mate is found who is both compatible and of high genetic quality. A high level of sexual disgust, 
especially towards lower quality potential mates, will help prevent early reproduction with such a mate. Thus, higher levels of sexual disgust should be observed in those pursuing slow strategies. Conversely, if one is pursuing a fast life history strategy, waiting for the perfect mate will be counterproductive and could prevent one from taking advantage of limited reproductive opportunities in an unpredictable environment. Thus, the pursuit of a fast strategy will be facilitated by having a lower than average level of sexual disgust. Interestingly, experimental research completed by Stevenson, Case, and Oaten (2011) demonstrated that sexual arousal can directly facilitate mating by temporarily reducing an individual's disgust sensitivity.

Thus far, there has been limited research into the relationship between disgust sensitivity and life history strategy. Gladden, Figueredo, and Jacobs (2009) found that individuals with slow life history strategies reported higher levels of moral and pathogen disgust. However, this study did not assess sensitivity to disgust in a sexual context. Tybur et al. (2009a) have argued that sexual disgust, which helps us to avoid biologically costly mates, is distinct from pathogen and moral disgust. Although there may be some overlap among the domains, sexual disgust is primarily directed towards potential mates who are genetically incompatible, of low intrinsic quality, or otherwise unlikely to make for a good reproductive partner (e.g., the very young and very old). A factor analysis conducted by Tybur et al. (2009a) found support for the three factor structure of disgust sensitivity, and this result was subsequently replicated by DeBruine, Jones, Tybur, Lieberman, and Griskevicius (2010). Thus, there is empirical support for these three distinct domains.

According to life history theory, environments that are stressful or unstable will cause organisms to shift resources from somatic effort to reproductive effort (Chisholm, 1993). In terms of how this shift will impact disgust sensitivity, the increased reproductive effort should be associated with an appreciable reduction in sexual disgust. The avoidance of contaminants and infectious diseases will continue to be of high importance for survival, even in unstable environments. However, because faster life history strategies are associated with greater risk taking and lower somatic effort, sensitivity to pathogen disgust may be decreased in those expressing faster strategies. Moral disgust is primarily directed towards individuals who display behaviors indicative of a selfish or untrustworthy partner. Since individuals expressing slow life history strategies are thought to form stronger ties to family, friends, and the community, these individuals may be more disgusted by violations of social norms and agreements. Thus, moral disgust sensitivity may also be higher among slow strategy individuals.

Broadly speaking, disgust is an avoidant reaction primarily directed towards threats to long-term health and success. Avoiding such threats is 
desirable for all individuals, but avoidance behaviors can also lead one to miss potential opportunities. Those who are less sensitive to disgust may take more risks in terms of exposure to contaminants or unscrupulous partners, but may also gain access to more immediate resources in the environment. Life history theory suggests that individuals pursuing a fast strategy are more willing to risk long-term somatic health to pursue short-term reproductive gains (Chisholm, 1993). Thus, a relatively low level of disgust sensitivity would be useful for those with fast life history strategies, as this will lead them pursue opportunities despite the presence of disgust-provoking stimuli. On the other hand, those with slower life history strategies prioritize long-term health and success, and a high sensitivity to disgust would lead to protective avoidance behaviors consistent with this strategy. Observed gender differences are consistent with this framework, as females tend to be more sensitive to disgust than males (Tyber, Bryan, Lieberman, Hooper, \& Merriman, 2011), and females also display significantly slower life history strategies than males (Dunkel, 2012; Copping, Campbell, \& Muncer, 2014).

Recently, some researchers have argued that life history strategy may not be fully captured by measures that treat it as a unidimensional variable running from fast to slow (see Copping, Campbell, \& Muncer, 2014; Copping, Campbell, Muncer, \& Richardson, 2017; Richardson, Chen, Dai, Brubaker, \& Nedelec, 2017). Existing psychometric measures of life history strategy may only tap into the K-factor, which includes long-term planning, quality of parental relationships, support from friends and relatives, community involvement, and pair-bonding (Richardson et al., 2017). However, this Kfactor does not appear to subsume mating competition and mating effort, which may be a separate dimension altogether (Copping et al., 2017; Richardson et al., 2017). While there is clearly a need for more research into the psychometrics of life history strategy, existing survey measures have been shown to be reliable and internally consistent in yielding $\mathrm{K}$-factor values that correlate with a number of relevant variables (see Figueredo et al., 2015). Although it may be distinct from mating effort, evidence suggests the $\mathrm{K}$-factor is a real variable with a unique identity (Richardson et al., 2017). In this study, we chose to focus on the $\mathrm{K}$-factor of life history and its relationship with disgust sensitivity.

\section{Current study}

The goal of the current study was to explore how the K-factor of life history strategy relates to the three domains of disgust. It was hypothesized that one component of a high $\mathrm{K}$ strategy involves an aversion towards biological objects and events that can cause long-term risks. As such, individuals with higher K- 
factor scores were predicted to show greater sensitivity to disgust than those with lower K-factor scores. We predicted that this relationship would be significant for all three domains of disgust, and strongest for sexual disgust due to its direct connection with reproductive strategy.

\section{METHOD}

\section{Participants and procedure}

A previous validation study for the Three Domains of Disgust Scale included a sample of 300 participants (Tybur et al., 2009a). We sought to approximate this sample size in the current study. Two hundred seventy-seven participants (140 males and 137 females) completed the online questionnaire. Seventy-six of the participants were students recruited from the psychology research pool at an urban public university in the mid-Atlantic region. The remaining 201 participants were recruited using Amazon's Mechanical Turk crowdsourcing service. All work received prior approval from the Institutional Review Board and was conducted in compliance with American Psychological Association ethical standards for the treatment of human participants.

K-factor was measured using the Mini-K Life History Battery (Figueredo et al., 2006). The Mini-K is a short form of the Arizona Life History Battery (Figueredo \& Gaxiola, 2007). Previous work has found this scale to exhibit high reliability and validity (see Figueredo et al., 2006). The Mini-K consists of 20 items (e.g., "I often make plans in advance") that use a seven-point rating scale ranging from ' -3 ' (disagree strongly) to ' +3 ' (agree strongly). Responses were averaged to yield individual scores, with higher scores indicating a high $\mathrm{K}$ (i.e. 'slow') strategy.

The Three Domains of Disgust Scale (TDDS) developed by Tybur, Lieberman, and Griskevicius (2009b) was used to measure disgust sensitivity. The TDDS consists of seven items for each of the three domains: pathogen disgust (e.g., "Seeing some mold on old leftovers in the refrigerator"), sexual disgust (e.g., "Finding out someone you don't like has sexual fantasies about you"), and moral disgust (e.g., "Forging someone's signature on a legal document"). Previous research has found high internal reliability in each of the three domains on this scale (Tybur et al., 2009a). Participants rated how disgusting they found each item on a seven-point rating scale. Responses were averaged for each participant to yield three composite scores, one for each disgust domain. These three values were also summed to generate overall disgust sensitivity values for each participant. Higher scores indicated greater disgust sensitivity. 
The use of the Mini-K to measure life history strategy and the TDDS to measure disgust sensitivity is problematic in that certain items may overlap these two constructs. Specifically, three items on the Mini-K deal with Experiences in Close Relationships (ECR): 'I have a close and warm relationship with my sexual partner.', 'I would rather have one than several sexual relationships at a time.' and 'I have to be closely attached to someone before I am comfortable having sex with them.' On the TDDS, many of the sexual disgust items include similar themes and situations (e.g., 'Bringing someone you just met back to your room to have sex'). To control for this content overlap bias, we calculated Mini-K scores both with and without the inclusion of the three ECR items. All analyses were run using both the full and adjusted (no ECR) Mini-K scores.

\section{Data analysis}

The associations between Mini-K scores and disgust sensitivity in each of the three domains were examined using Pearson product-moment correlation coefficients.

\section{RESULTS}

\section{Descriptive statistics}

The Mechanical Turk sample was somewhat older $(M=34.9, S D=10.00)$, on average, than the college sample $(M=27.6, S D=11.30), t(275)=-5.22$, $p<.001$. The college participants scored higher on the Mini-K $(M=1.26$, $S D=.66)$ and the TDDS $(M=14.47, S D=2.78)$ than the Mechanical Turk sample (Mini-K: $M=.92, S D=.90$; TDDS: $M=11.43, S D=3.27$ ). These differences were statistically significant for both Mini-K scores, $t(182.8)=$ $3.46, p=.001$, and TDDS scores, $t(275)=7.17, p<.001$. We chose to focus on the combined sample to maximize statistical power and include a broad range of ages. Partial correlations were examined while controlling for sample source, as discussed below.

Mini-K scores ranged from -2.10 to $2.75(M=1.01, S D=.85)$. Scores on the TDDS composite ranged from 3.00 to $20.29(M=12.26, S D=3.42)$. Scores ranged from one to seven on each of the three disgust domains, pathogen $(M=$ $4.59, S D=1.31)$, moral $(M=4.44, S D=1.57)$, and sexual $(M=3.24$, $S D=1.52)$. There was high internal consistency for both the Mini-K (20 items; $\alpha=.84$ ) and the TDDS (21 items; $\alpha=.91$ ). Principal Components Analysis confirmed that the TDDS fit the three factor structure proposed by Tybur et al. (2009a), with the first factor (corresponding to the seven moral disgust items) 
explaining $35 \%$ of the variance, the second factor (corresponding to the seven pathogen disgust items) explaining $15 \%$ of the variance, and the third factor (corresponding to the seven sexual disgust items) explaining $12 \%$ of the variance.

\section{Pearson correlations}

Table 1 displays the results of the Pearson correlation tests. Examination of the composite scores revealed a significant positive correlation between Mini-K scores and TDDS scores $(r(275)=.308, p<.001)$. This correlation remained significant when Mini-K scores were calculated without the three ECR items in order to avoid potential overlap between the measures $(r(275)=.263$, $p<.001)$. Thus, higher $\mathrm{K}$ strategies were associated with higher levels of disgust sensitivity (see Figure 1).

Table 1. Correlations between disgust sensitivity and Mini-K Scores

\begin{tabular}{|l|c|c|c|c|c|}
\hline Measure & 1 & 2 & 3 & 4 & 5 \\
\hline 1. Mini-K Score & - & & & & \\
\hline 2. Mini-K without ECR Items & .977 & - & & & \\
\hline 3. Disgust Sensitivity Total & .308 & .263 & - & & \\
\hline 4. Pathogen Disgust Sensitivity & .224 & .201 & .748 & - & \\
\hline 5. Sexual Disgust Sensitivity & .252 & .197 & .815 & .479 & - \\
\hline 6. Moral Disgust Sensitivity & .241 & .214 & .766 & .336 & .408 \\
\hline
\end{tabular}

Note. All correlations are significant at $\mathrm{p}<.01 . \mathrm{N}=277$.

The relationships between Mini-K scores and each of the three domains of disgust sensitivity on the TDDS were examined using Pearson correlation tests. The analysis revealed significant positive relationships between Mini-K scores and all three disgust domains, pathogen (see Table 1). When Mini-K scores were calculated without the three ECR items, they remained significantly correlated with all three disgust domains. 


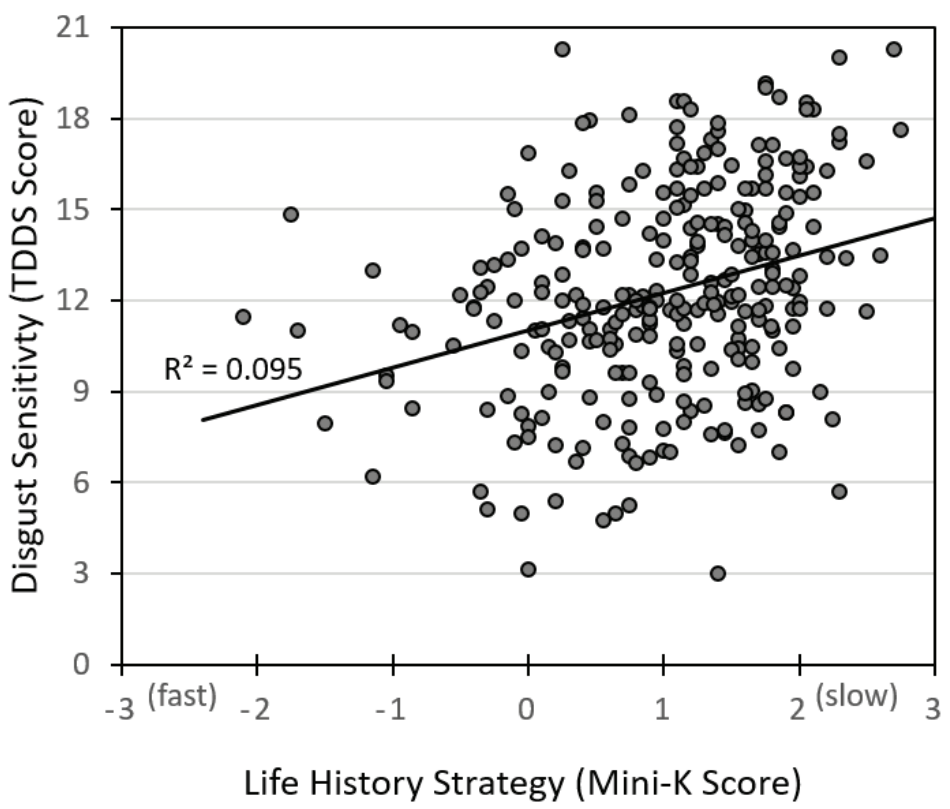

Figure 1. Scatterplot depicting the relationship between scores on the Mini-K Life History Battery and scores on the Three Domains of Disgust Scale.

Table 2. Partial correlations between disgust sensitivity and Mini-K Scores while controlling for sample

\begin{tabular}{|l|c|c|c|c|c|}
\hline Measure & 1 & 2 & 3 & 4 & 5 \\
\hline 1. Mini-K Score & - & & & & \\
\hline 2. Mini-K without ECR Items & .977 & - & & & \\
\hline 3. Disgust Sensitivity Total & .263 & .218 & - & & \\
\hline 4. Pathogen Disgust Sensitivity & .175 & .154 & .709 & - & \\
\hline 5. Sexual Disgust Sensitivity & .211 & .157 & .794 & .418 & - \\
\hline 6. Moral Disgust Sensitivity & .202 & .177 & .743 & .261 & .353 \\
\hline
\end{tabular}

Note. All correlations are significant at $\mathrm{p}<.01 . \mathrm{N}=277$.

As noted above, our two samples differed significantly in terms of both TDDS and Mini-K scores. To ensure that our observed results were not an 
artifact of these differences, we calculated partial correlations between variables of interest while controlling for sample. As shown in Table 2, all correlations remained positive and significant, although some effect sizes were marginally reduced.

\section{DISCUSSION}

The goal of this study was to explore the relationship between the K-factor of life history strategy and sensitivity to disgust in each of the three domains defined by Tybur et al. (2009a). We predicted that greater sensitivity to disgust would be associated with higher scores on the K-factor of life history strategy, and that this effect would be largest for sexual disgust. While we did find a significant correlation between Mini-K scores and sensitivity to sexual disgust, the effect sizes for the correlations with Mini-K scores were similar across the three domains $\left(r^{2}=.05\right.$ for pathogen, $r^{2}=.06$ for moral, and $r^{2}=.06$ for sexual). Without the inclusion of the three ECR items on the Mini-K, the observed effect size for the correlation with sexual disgust became slightly smaller $\left(r^{2}=.04\right)$, but remained significant. These findings suggest that individuals higher in Kfactor are more sensitive to disgust-provoking stimuli in general, rather than being particularly sensitive to stimuli in one or two domains.

In conclusion, individuals expressing high K (i.e., 'slow') life history strategies are more sensitive to disgust across a variety of domains and stimuli. When pathogen, moral, and sexual disgust sensitivity are examined separately, they are each significantly related to scores on a life history battery. The strengths of these associations are roughly equal across the three disgust domains, suggesting that slower life history strategies tend to involve higher levels of disgust sensitivity in general, rather than domain-specific increases in disgust sensitivity.

Our study is limited by its correlational nature, which prevents us from inferring a causal relationship between disgust sensitivity and life history strategy. In addition, we did not include a direct measure of mating effort or mate competition. As noted earlier, recent work has suggested that there may be more than one dimension to life history strategy, and that measures of K-factor including the Mini-K may not adequately assess mating competition (Richardson et al., 2017). Nevertheless, there does appear to be an underlying $\mathrm{K}$-factor dimension, even if it does not fully encompass all the variation in life history strategies (see Figueredo et al., 2015; Richardson et al., 2017). Although we did not assess mating effort, it seems plausible that disgust sensitivity, particularly for sexual disgust, would be lower in those who put more effort into mating and mate competition. Future research should explore this possibility, and work to clarify the underlying structure of life history strategy. 
These results are consistent with life history theory, in that individuals high in K-factor are more likely to display avoidance behaviors towards potential threats to long-term health and fitness, while those low in K-factor tend to take more risks in pursuit of short-term reproductive gains. Our findings suggest that high $\mathrm{K}$ strategies are characterized in part by a greater sensitivity to disgust. This increased sensitivity likely helps these individuals avoid disease, toxins, and interactions with untrustworthy partners. The downside to this approach is that avoidance can also prevent one from pursuing certain immediate opportunities. Determining which environmental and genetic factors tend to predispose one towards greater disgust sensitivity will require additional research.

\section{ACKNOWLEDGEMENTS}

The authors wish to thank Dr. Sally Farley for providing helpful feedback on an earlier draft of this paper.

\section{REFERENCES}

Buss, D. M. (1999). Evolutionary psychology: The new science of the mind. Needham Heights, MA, US: Allyn \& Bacon.

Cabeza de Baca, T., \& Figueredo, A. J. (2014). The cognitive ecology of Mexico: Climatic and socio-cultural effects on life history strategies and cognitive abilities. Intelligence, 47, 6371. http://doi.org/10.1016/j.intell.2014.08.007

Cannon, P. R., Schnall, S., \& White, M. (2010). Transgressions and Expressions. Social Psychological and Personality Science, 2(3), 325-331. https://doi.org/10.1177/1948550610390525

Chisholm, J. S. (1993). Death, hope, and sex: Life-history theory and the development of reproductive strategies. Current Anthropology, 34(1), 1-24. http://doi.org/10.1086/204131

Chisholm, J. S., Quinlivan, J. A., Petersen, R. W., \& Coall, D. A. (2005). Early stress predicts age at menarche and first birth, adult attachment, and expected lifespan. Human Nature, 16(3), 233-265. http://doi.org/10.1007/s12110-005-1009-0

Copping, L. T., \& Campbell, A. (2015). The environment and life history strategies: Neighborhood and individual-level models. Evolution and Human Behavior, 36(3), 182190. http://doi.org/10.1016/j.evolhumbehav.2014.10.005

Copping, L. T., Campbell, A., \& Muncer, S. (2013). Impulsivity, sensation seeking and reproductive behaviour: A life history perspective. Personality and Individual Differences, 54(8), 908-912. http://doi.org/10.1016/j.paid.2013.01.003

Copping, L. T., Campbell, A., \& Muncer, S. (2014). Psychometrics and life history strategy: The structure and validity of the High K Strategy Scale. Evolutionary Psychology, 12(1), 147470491401200130. https://doi.org/10.1177/147470491401200115

Copping, L. T., Campbell, A., Muncer, S., \& Richardson, G. B. (2017). The Psychometric evaluation of human life histories. Evolutionary Psychology, 15(1), 1474704916663727. https://doi.org/10.1177/1474704916663727 
DeBruine, L. M., Jones, B. C., Tybur, J. M., Lieberman, D., \& Griskevicius, V. (2010). Women's preferences for masculinity in male faces are predicted by pathogen disgust, but not by moral or sexual disgust. Evolution and Human Behavior, 31(1), 69-74. http://doi.org/10.1016/j.evolhumbehav.2009.09.003

Dillon, H. M., Adair, L. E., \& Brase, G. L. (2015). A threatening exchange: Gender and life history strategy predict perceptions and reasoning about sexual harassment. Personality and Individual Differences, 72, 195-199. http://doi.org/10.1016/j.paid.2014.09.002

Dillon, H. M., Adair, L. E., Wang, Z., \& Johnson, Z. (2013). Slow and steady wins the race: Life history, mate value, and mate settling. Personality and Individual Differences, 55(5), 612 618. http://doi.org/10.1016/j.paid.2013.05.015

Druschel, B., \& Sherman, M. (1999). Disgust sensitivity as a function of the Big Five and gender. Personality and Individual Differences, 26, 739-748. http://doi.org/10.1016/S01918869(98)00196-2

Dunkel, C. S. (2012). Do self-report measures of life history strategy exhibit the hypothesized differences between blacks and whites predicted by Differential K theory? Personality and Individual Differences, 52(6), 759-761. https://doi.org/10.1016/j.paid.2011.12.035

Dunkel, C. S., Mathes, E., \& Beaver, K. M. (2013). Life history theory and the general theory of crime: Life expectancy effects on low self-control and criminal intent. Journal of Social, Evolutionary, and Cultural Psychology, 7(1), 12-23. http://doi.org/10.1037/h0099177

Ekman, P. (1992). An argument for basic emotions. Cognition and Emotion, 6(3-4), 169-200. http://doi.org/10.1080/02699939208411068

Ellis, B. J. (2004). Timing of pubertal maturation in girls: An integrated life history approach. Psychological Bulletin, 130(6), 920-958.

Ellis, B. J., Figueredo, A. J., Brumbach, B. H., \& Schlomer, G. L. (2009). Fundamental dimensions of environmental risk: The impact of harsh versus unpredictable environments on the evolution and development of life history strategies. Human Nature, 20(2), 204-268. http://doi.org/10.1007/s12110-009-9063-7

Fessler, D. M. T., \& Navarrete, C. D. (2003). Domain-specific variation in disgust sensitivity across the menstrual cycle. Evolution and Human Behavior, 24, 406-417. http://doi.org/10.1016/S1090-5138(03)00054-0

Figueredo, A., \& Rushton, J. (2009). Evidence for shared genetic dominance between the general factor of personality, mental and physical health, and life history traits. Twin Research and Human Genetics, 12(6), 555-563. http://doi.org/10.1375/twin.12.6.555

Figueredo, A. J., \& Gaxiola, R. J. (2007). The Arizona-Sonora Life History Battery. [Electronic Version]. Retrieved from http://www.u.arizona.edu/ ajf/alhb.html

Figueredo, A. J., Vasquez, G., Brumbach, B. H., \& Schneider, S. R. (2004). The heritability of life history strategy: The K-Factor, covitality, and personality. Social Biology, 51(3/4), 121143. http://doi.org/10.1080/19485565.2004.9989090

Figueredo, A. J., Vásquez, G., Brumbach, B. H., Schneider, S. M. R., Sefcek, J. A., Tal, I. R., Hill, D., Wenner, C. J., \& Jacobs, W. J. (2006). Consilience and Life History Theory: From genes to brain to reproductive strategy. Evolutionary Developmental Psychology, 26(2), 243-275. http://doi.org/10.1016/j.dr.2006.02.002

Fischer, A. H., \& Roseman, I. J. (2007). Beat them or ban them: The characteristics and social functions of anger and contempt. Journal of Personality and Social Psychology, 93(1), 103115. https://doi.org/10.1037/0022-3514.93.1.103

Giner-Sorolla, R., \& Chapman, H. A. (2016). Beyond purity. Psychological Science, 28(1), 8091. https://doi.org/10.1177/0956797616673193

Giner-Sorolla, R., \& Espinosa, P. (2011). Social cuing of guilt by anger and of shame by disgust. Psychological Science, 22(1), 49-53. https://doi.org/10.1177/0956797610392925 
Gladden, P. R., Figueredo, A. J., \& Jacobs, W. J. (2009). Life history strategy, psychopathic attitudes, personality, and general intelligence. Personality and Individual Differences, 46(3), 270-275. http://doi.org/10.1016/j.paid.2008.10.010

Griskevicius, V., Delton, A. W., Robertson, T. E., \& Tybur, J. M. (2011a). Environmental contingency in life history strategies: The influence of mortality and socioeconomic status on reproductive timing. Journal of Personality and Social Psychology, 100(2), 241-254. http://doi.org/10.1037/a0021082

Griskevicius, V., Tybur, J. M., Delton, A. W., \& Robertson, T. E. (2011b). The influence of mortality and socioeconomic status on risk and delayed rewards: A life history theory approach. Journal of Personality and Social Psychology, 100(6), 1015-1026. http://doi.org/10.1037/a0022403

Hackman, J., \& Hruschka, D. (2013). Fast life histories, not pathogens, account for state-level variation in homicide, child maltreatment, and family ties in the U.S. Evolution and Human Behavior, 34(2), 118-124. http://doi.org/10.1016/j.evolhumbehav.2012.11.002

Haidt, J. (2003). The moral emotions. In R. J. Davidson, K. R. Scherer, \& H. H. Goldsmith (Eds.), Handbook of affective sciences (852-870). Oxford: Oxford University Press.

Haidt, J., McCauley, C., \& Rozin, P. (1994). Individual differences in sensitivity to disgust: A scale sampling seven domains of disgust elicitors. Personality and Individual Differences, 16(5), 701-713. http://doi.org/10.1016/0191-8869(94)90212-7

Haidt, J., Rozin, P., McCauley, C., \& Imada, S. (1997). Body, psyche, and culture: The relationship between disgust and morality. Psychology and Developing Societies, 9(1), $107-$ 131. http://doi.org/10.1177/097133369700900105

Koehler, N., \& Chisholm, J. S. (2007). Early psychosocial stress predicts extra-pair copulations. Evolutionary Psychology, 5(1), 184-201. http://doi.org/10.1177/147470490700500111

MacArthur, R. H., \& Wilson, E. O. (1967). The Theory of Island Biogeography (REV-Revised). Princeton University Press. Retrieved from http://www.jstor.org/stable/j.ctt19cc1t2

Nussbaum, M., C. (2009). Hiding from humanity: Disgust, shame, and the law. Princeton University Press.

Olatunji, B. O., Adams, T., Ciesielski, B., David, B., Sarawgi, S., \& Broman-Fulks, J. (2012). The Three Domains of Disgust Scale: Factor structure, psychometric properties, and conceptual limitations. Assessment, 9(2), 205-225. http://doi.org/10.1177/1073191111432881

Rempel, J. K., \& Baumgartner, B. (2003). The relationship between attitudes towards menstruation and sexual attitudes, desires, and behavior in women. Archives of Sexual Behavior, 32(2), 155-163. http://doi.org/10.1023/A:1022404609700

Richardson, G. B., Chen, C.-C., Dai, C.-L., Brubaker, M. D., \& Nedelec, J. L. (2017). The psychometrics of the Mini-K. Evolutionary Psychology, 15(1), 1474704916682034. https://doi.org/10.1177/1474704916682034

Rozin, P., Haidt, J., \& McCauley, C. R. (1993). Disgust. In M. Lewis \& J. M. Haviland-Jones (Eds.), Handbook of emotions. (pp. 575-594). New York, NY, US: Guilford Press.

Rozin, P., Haidt, J., \& McCauley, C. R. (2008). Disgust. In M. Lewis, J. M. Haviland-Jones, \& L. F. Barrett (Eds.), Handbook of emotions (3rd ed.). (pp. 757-776). New York, NY, US: Guilford Press.

Rushton, J. P. (1985). Differential K theory: The sociobiology of individual and group differences. Personality and Individual Differences, 6(4), 441-452. http://doi.org/10.1016/0191-8869(85)90137-0

Stearns, S. C. (1976). Life-history tactics: A review of the ideas. The Quarterly Review of Biology, 51(1), 3-47. https://doi.org/10.1086/409052

Stearns, S. C. (1989). Trade-offs in life-history evolution. Functional Ecology, 3(3), 259-268. https://doi.org/10.2307/2389364 
Stevenson, R. J., Case, T. I., \& Oaten, M. J. (2011). Effect of self-reported sexual arousal on responses to sex-related and non-sex-related disgust cues. Archives of Sexual Behavior, 40(1), 79-85. http://doi.org/10.1007/s10508-009-9529-z

Stormer, C., \& Lummaa, V. (2014). Increased mortality exposure within the family rather than individual mortality experiences triggers faster life-history strategies in historic human populations. PloS One, 9(1). http://doi.org/10.1371/journal.pone.0083633

Tybur, J. M., Bryan, A. D., Lieberman, D., Caldwell Hooper, A. E., \& Merriman, L. A. (2011). Sex differences and sex similarities in disgust sensitivity. Personality \& Individual Differences, 51(3), 343-348. https://doi.org/10.1016/j.paid.2011.04.003

Tybur, J. M., Lieberman, D., \& Griskevicius, V. (2009a). Microbes, mating, and morality: Individual differences in three functional domains of disgust. Journal of Personality and Social Psychology, 97(1), 103-122. http://doi.org/10.1037/a0015474

Tybur, J. M., Lieberman, D., \& Griskevicius, V. (2009b). Three-domain disgust scale. PsycTESTS. http://doi.org/10.1037/t09980-000

van der Linden, D., van Klaveren, D., \& Dunkel, C. S. (2015). Emotional intelligence (EI) is an indicator of a slow life history strategy: A test of ability and trait EI. Personality and Individual Differences, 73, 84-87. http://doi.org/10.1016/j.paid.2014.09.027

van Leeuwen, F., Koenig, B. L., Graham, J., \& Park, J. H. (2014). Moral concerns across the United States: Associations with life-history variables, pathogen prevalence, urbanization, cognitive ability, and social class. Evolution and Human Behavior, 35(6), 464-471. http://doi.org/10.1016/j.evolhumbehav.2014.06.005

Wilson, M., \& Daly, M. (1997). Life expectancy, economic inequality, homicide, and reproductive timing in Chicago neighbourhoods. BMJ: British Medical Journal (International Edition), 314(7089), 1271-1274. 